Article

\title{
Synthesis, Crystal and Molecular Structure Studies and DFT Calculations of Phenyl Quinoline-2-Carboxylate and 2-Methoxyphenyl Quinoline-2-Carboxylate; Two New Quinoline-2 Carboxylic Derivatives
}

\section{Edakot Fazal ${ }^{1}$, Jerry P. Jasinski ${ }^{2, *}$, Brian J. Anderson ${ }^{2}$, Manpreet Kaur ${ }^{3}$, Subban Nagarajan ${ }^{4}$ and Belgur Satyanarayana Sudha ${ }^{1}$}

1 Department of Chemistry, Yuvaraja's College, University of Mysore, Mysore-570 005, India; E-Mails: edakot@gmail.com (E.F.); sudha2k2@rediffmail.com (B.S.S.)

2 Department of Chemistry, Keene State College, 229 Main Street, Keene, NH 03435-2001, USA; E-Mail: banderson1@keene.edu

3 Department of Studies in Chemistry, University of Mysore, Manasagangotri, Mysore 570 006, India; E-Mail: manpreet.kaur2488@hotmail.com

4 Spice and Flavor Science Department, CSIR-Central Food Technological Research institute, Mysore 570005, India; E-Mail: nagarajan@cftri.res.in

* Author to whom correspondence should be addressed; E-Mail: jjasinski@keene.edu; Tel.: +603-358-2563.

Academic Editor: Ivana R. Evans

Received: 15 December 2014 / Accepted: 12 January 2015 / Published: 12 February 2015

\begin{abstract}
The crystal and molecular structures of the title compounds, phenyl quinoline-2-carboxylate and 2-methoxyphenyl quinoline-2-carboxylate, two new derivatives of quinolone-2-carboxylic acid, are reported and confirmed by single crystal X-ray diffraction and spectroscopic data. Compound (I), $\mathrm{C}_{16} \mathrm{H}_{11} \mathrm{NO}_{2}$, crystallizes in the monoclinic space group $P 2{ }_{1} / c$, with 8 molecules in the unit cell. The unit cell parameters are $a=14.7910(3) \AA ; b=5.76446(12) \AA ; c=28.4012(6) \AA ; \beta=99.043(2)^{\circ} ; V=2391.45(9) \AA^{3}$. Compound (II), $\mathrm{C}_{17} \mathrm{H}_{13} \mathrm{NO}_{5}$, crystallizes in the monoclinic space group $P 21 / n$ with 4 molecules in the unit cell. The unit cell parameters are $a=9.6095(3) \AA ; b=10.8040(3) \AA$; $c=13.2427(4) \AA ; \beta=102.012(3)^{\circ} ; V=1344.76(7) \AA^{3}$. Density functional theory (DFT) geometry optimized molecular orbital calculations were performed and frontier molecular orbitals of each compound are displayed. Correlation between the calculated molecular orbital energies $(\mathrm{eV})$ for the surfaces of the frontier molecular orbitals to the electronic
\end{abstract}


excitation transitions from the absorption spectra of each compound has been proposed. Additionally, similar correlations observed among six closely related compounds examining small structural differences to their frontier molecular orbital surfaces and from their DFT molecular orbital energies, provide further support for the suggested assignments of the title compounds.

Keywords: X-ray crystal structure; DFT molecular orbital calculations; frontier molecular orbitals

\section{Introduction}

Quinoline-2 carboxylic acid derivatives are a class of important materials as anti-tuberculosis agents, as fluorescent reagents, hydrophobic field-detection reagents, visualization reagents, fluorescent labelled peptide probes and as anti-hyperglycemics. Quinoline derivatives represent a major class of heterocycles and are found in natural products [1,2], numerous commercial products, including fragrances, dyes [3] and biologically active compounds [4,5]. Quinoline alkaloids such as quinine, chloroquin, mefloquine and amodiaquine are used as efficient drugs for the treatment of malaria [6]. Quinoline as a privileged scaffold in cancer drug discovery is also published [7]. The crystal structures of 4-methylphenyl quinoline-2carboxylate [8], 4-chloro-3-methylphenyl quinoline-2-carboxylate [9], 4-chlorophenyl quinoline-2carboxylate [10], 3,4-dimethylphenyl quinoline-2-carboxylate [11], 2-isopropyl-5-methylcyclohexyl quinoline-2-carboxylate [12], 2,5-dimethylphenyl quinoline-2-carboxylate [13] and the synthesis and theoretical studies of four Schiff bases derived from 4-hydrazinyl-8-(trifluoromethyl) quinoline [14] have been reported. In view of the importance of quinolines, we report here the synthesis, crystal structures and theoretical calculations for two new derivatives of quinoline-2 carboxylic acid, namely, phenyl quinoline-2-carboxylate (I) and 2-methoxyphenyl quinoline-2-carboxylate (II) (Figure 1) supported by density functional theory (DFT) calculations correlating the calculated molecular orbital energies (eV) for the surfaces of the frontier molecular orbitals to the electronic excitation transitions from the absorption spectra of each compound.

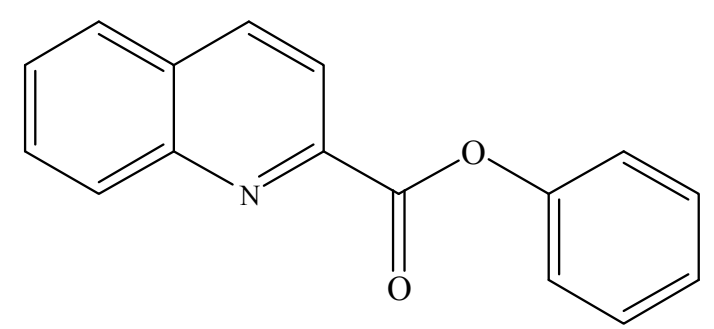

(I)

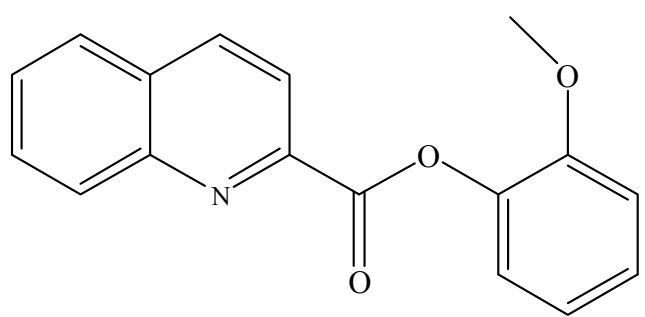

(II)

Figure 1. The molecular structures of $\mathrm{C}_{16} \mathrm{H}_{11} \mathrm{NO}_{2}$ (I) and $\mathrm{C}_{17} \mathrm{H}_{13} \mathrm{NO}_{3}$ (II). 


\section{Results and Discussion}

\subsection{Structural Study of (I): Phenyl Quinoline-2-Carboxylate}

The asymmetric unit of In (I), $\mathrm{C}_{16} \mathrm{H}_{11} \mathrm{NO}_{2}$, contains two molecules. Bond lengths are in normal ranges [15] (Table 1). The dihedral angle between the mean planes of the quinoline and phenyl rings is 55.3(9) $)^{\circ}$ in molecule A and 56.4(9) ${ }^{\circ}$ in molecule B (Figure 2a). The carboxylate group is twisted by $3.8(2)^{\circ}(\mathrm{A})$ and $3.5(3)^{\circ}(\mathrm{B})$, respectively from the mean plane of the quinoline group. A weak C12B---H12B O1A intermolecular interaction is observed between a carboxyl oxygen atom and a phenyl hydrogen atom from nearby molecules within the asymmetric unit forming dimers stacked along the $a$ axis of the unit cell (Figure 2b). No classical hydrogen bonds were observed. Additional weak C---H O intermolecular interactions and $\pi-\pi$ stacking interactions between the two rings of the quinoline group and carboxyl oxygen atoms of nearby molecules are also observed (Table 2).

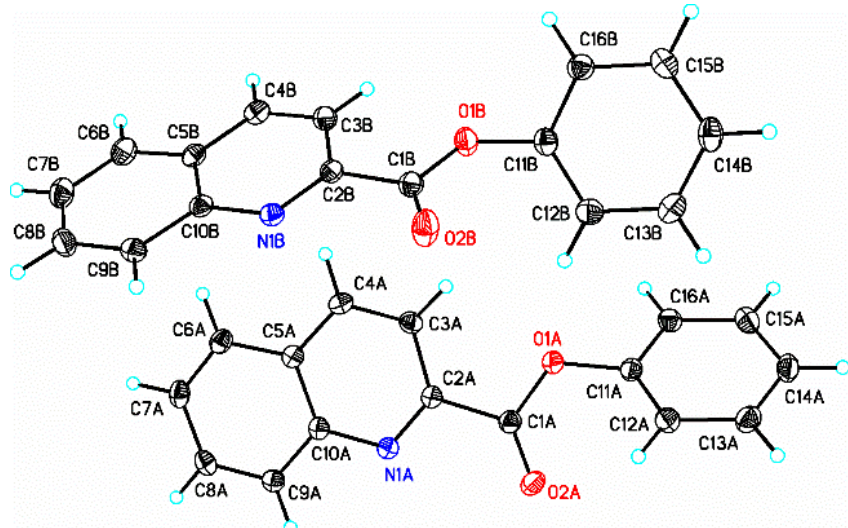

(a)

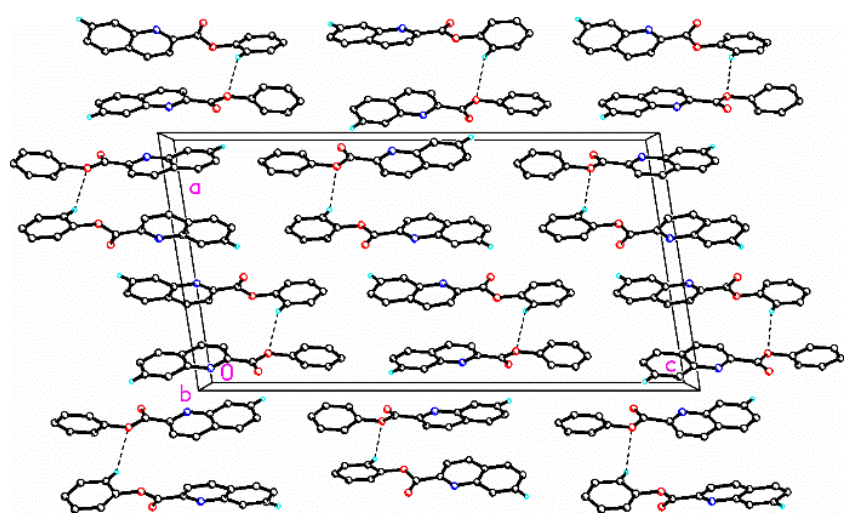

(b)

Figure 2. (a) Molecular structure of $\mathrm{C}_{16} \mathrm{H}_{11} \mathrm{NO}_{2}$ (I), showing the atom numbering scheme with $30 \%$ probability ellipsoids; (b) Packing diagram for (I) viewed along the $b$ axis. $\mathrm{H}$ atoms not involved in hydrogen bonding have been removed for clarity.

Table 1. Selected crystal and DFT* bond lengths $(\AA)$, bond angles $\left(^{\circ}\right)$, and torsion angles $\left(^{\circ}\right)$ for (I), $\mathbf{C}_{\mathbf{1 6}} \mathrm{H}_{11} \mathbf{N O}_{2}$.

\begin{tabular}{ccccrc}
\hline Atoms(I) & Distance(I) & DFT(I) & Atoms(I) & Distance(I) & DFT(I) \\
\hline O1A-C1A & $1.354(3)$ & $* 1.373$ & O2A-C1A & $1.192(3)$ & $* 1.204$ \\
O1A-C11A & $1.408(2)$ & $* 1.397$ & N1A-C2A & $1.313(3)$ & $* 1.321$ \\
N1A-C10A & $1.369(3)$ & $* 1.359$ & C1A-C2A & $1.510(3)$ & $* 1.509$ \\
C2A-C3A & $1.416(3)$ & $* 1.422$ & C3A-C4A & $1.362(3)$ & $* 1.374$ \\
C6A-C7A & $1.361(3)$ & $* 1.377$ & C8A-C9A & $1.373(3)$ & $* 1.375$ \\
C9A-C10A & $1.414(3)$ & $* 1.422$ & C12A-C13A & $1.384(3)$ & $* 1.395$ \\
C14A-C15A & $1.390(3)$ & $* 1.396$ & O1B-C1B & $1.354(3)$ & $* 1.397$ \\
O2B-C1B & $1.197(3)$ & $* 1.204$ & O1B-C11B & $1.410(2)$ & $* 1.397$ \\
N1B-C2B & $1.316(3)$ & $* 1.321$ & N1B-C10B & $1.369(3)$ & $* 1.359$ \\
C13B-C14B & $1.387(4)$ & $* 1.396$ & C15B-C16B & $1.389(3)$ & $* 1.395$ \\
\hline
\end{tabular}


Table 1. Cont.

\begin{tabular}{cccccc}
\hline Atoms(I) & Angles(I) & DFT(I) & Atoms(I) & Angles(I) & DFT(I) \\
\hline C1A-O1A-C11A & $120.80(16)$ & $* 121.01$ & C2A-N1A-C10A & $117.27(18)$ & $* 118.24$ \\
O1A-C1A-O2A & $124.48(19)$ & $* 124.54$ & O1A-C1A-C2A & $109.42(17)$ & $* 110.02$ \\
O2A-C1A-C2A & $126.08(19)$ & $* 126.44$ & N1A-C2A-C1A & $114.84(18)$ & $* 114.75$ \\
N1A-C2A-C3A & $124.48(18)$ & $* 123.74$ & C3A-C2A-C1A & $120.65(18)$ & $* 121.51$ \\
C4A-C3A-C2A & $118.52(19)$ & $* 118.54$ & C3A-C4A-C5A & $119.70(19)$ & $* 119.76$ \\
C4A-C5A-C6A & $123.30(19)$ & $* 123.68$ & C7A-C6A-C5A & $120.2(2)$ & $* 120.30$ \\
C9A-C8A-C7A & $120.9(3)$ & $* 120.57$ & N1A-C10A-C5A & $122.32(18)$ & $* 122.55$ \\
N1A-C10A-C9A & $118.32(19)$ & $* 118.31$ & C9A-C10A-C5A & $119.36(18)$ & $* 119.14$ \\
C12A-C11A-O1A & $122.01(19)$ & $* 122.70$ & C12A-C11A-C16A & $122.26(19)$ & $* 121.25$ \\
C16A-C11A-O1A & $115.47(18)$ & $* 115.93$ & C11A)-12A-C13A & $118.5(3)$ & $* 118.65$ \\
C16A-C15A-C14A & $120.3(2)$ & $* 120.16$ & C1B-O1B-C11B & $119.21(16)$ & $* 121.01$ \\
C2B-N1B-C10B & $117.52(18)$ & $* 118.24$ & O2B-C1B-O1B & $124.19(19)$ & $* 125.44$ \\
O1B-C1B-C2B & $109.75(79)$ & $* 110.02$ & O2B-C1B-C2B & $126.05192)$ & $* 126.44$ \\
N1B-C2B-C1B & $114.12(18)$ & $* 114.75$ & N1B-C2B-C3B & $124.43(19)$ & $* 123.74$ \\
C8B-C9B-C10B & $120.1(2)$ & $* 120.26$ & N1B-C10B-C5B & $121.97(19)$ & $* 122.55$ \\
N1B-C10B-C9B & $118.69(19)$ & $* 118.31$ & C12B-C11B-O1B & $120.97(19)$ & $* 122.70$ \\
\hline Atoms(I) & Torsion(I) & DFT(I) & Atoms(I) & Torsion(I) & DFT(I) \\
\hline O1A-C1A-C2A-N1A & $175.65(17)$ & $* 178.71$ & O1A-C1A-C2A-C3A & $-2.9(3)$ & $*-1.51$ \\
O2A-C1A-C2A-N1A & $-2.8(3)$ & $* 1.07$ & O2A-C1A-C2A-C3A & $178.7(2)$ & $* 178.71$ \\
O1A-C11A-C12A-C13A & $-174.10(19)$ & $*-176.19$ & O1A-C11A-C16A-C15A & $175.39(18)$ & $* 176.26$ \\
N1A-C2A-C3A-C4A & $0.8(3)$ & $* 0.11$ & C1A-O2A-C11A-C12A & $-57.0(3)$ & $*-47.75$ \\
C1A-O2A-C11A-C16A & $128.7(2)$ & $* 136.27$ & C2A-N1A-C10A-C9A & $178.75(17)$ & $* 179.87$ \\
C4A-C5A-C10A-N1A & $0.6(3)$ & $* 0.03$ & C10A-N1A-C2A-C1A & $-178.67(16)$ & $*-170.93$ \\
O1B-C1B-C2B-N1B & $175.70(17)$ & $* 178.71$ & O1B-C1B-C2B-C3B & $-4.5(3)$ & $*-1.51$ \\
O2B-C1B-C2B-N1B & $-4.1(3)$ & $*-1.07$ & O2B-C1B-C2B-C3B & $175.7(2)$ & $* 178.71$ \\
O1B-C11B-C12B-C13B & $175.20(18)$ & $* 176.19$ & O1B-C11B-C16B-C15B & $-176.16(18)$ & $*-176.19$ \\
C4B-C5B-C10B-N1B & $-2.4(3)$ & $*-0.03$ & C10B-N1B-C2B-C3B & $1.5(3)$ & $* 0.15$ \\
\hline & & & & &
\end{tabular}

Table 2. Weak Intermolecular Interactions for (I) $\mathrm{C}_{16} \mathrm{H}_{11} \mathrm{NO}_{2}$, $\left(\AA\right.$ and $\left.{ }^{\circ}\right)$.

\begin{tabular}{ccccc}
\hline D---H & $\boldsymbol{d}(\mathbf{D}---\mathbf{H})$ & $\boldsymbol{d}(\mathbf{H} . . . \mathbf{A})$ & $\boldsymbol{d}(\mathbf{D} . . . \mathbf{A})$ & $<$ (DHA) \\
\hline C8A---H8A...O2A ${ }^{\# 1}$ & 0.95 & 2.64 & $3.418(3)$ & 139.6 \\
C8B---H8B...O2B \#2 & 0.95 & 2.95 & $3.38132)$ & 141.5 \\
C12B---H12B...O1A & 0.95 & 2.69 & $3.498(3)$ & 143.5 \\
Cg1---Cg1 \#3 & - & - & - & $3.8913(11)$ \\
Cg1---Cg2 \#3 & - & - & - & $3.7842(12)$ \\
Cg5---Cg5 ${ }^{\# 4}$ & - & - & - & $3.8576(11)$ \\
Cg5---Cg6 & - & - & - & $3.9654(12)$ \\
\hline
\end{tabular}

Notes: Symmetry transformations used to generate equivalent atoms: ${ }^{\# 1} 2-x, 2-y, 1-z ;{ }^{\# 2} 1-x, 1-y, 1-z$; ${ }^{\# 3} 2-x, 1-y, 1-z ;{ }^{\# 4} 1-x,-y, 1-z ; \mathrm{Cg} 1=\mathrm{N} 1 \mathrm{~A} / \mathrm{C} 2 \mathrm{~A} / \mathrm{C} 3 \mathrm{~A} / \mathrm{C} 4 \mathrm{~A} / \mathrm{C} 5 \mathrm{~A} / \mathrm{C} 10 \mathrm{~A} ; \mathrm{Cg} 2=\mathrm{C} 5 \mathrm{~A}-\mathrm{C} 10 \mathrm{~A}$; $\mathrm{Cg} 5=\mathrm{N} 1 \mathrm{~B} / \mathrm{C} 2 \mathrm{~B} / \mathrm{C} 3 \mathrm{~B} / \mathrm{C} 4 \mathrm{~B} / \mathrm{C} 5 \mathrm{~B} / \mathrm{C} 10 \mathrm{~B} ; \mathrm{Cg} 6=\mathrm{C} 5 \mathrm{~B}-\mathrm{C} 10 \mathrm{~B}$.

After a DFT geometry optimization calculation for (I), the dihedral angle between the mean planes of the quinoline and phenyl rings becomes $46.9(1)^{\circ}$, a decrease of $8.4(8)^{\circ}$ in molecule $\mathrm{A}$ or $9.5(8)^{\circ}$ in molecule B (Figure 2a). The mean plane of the carboxylate group $(\mathrm{O} 2 / \mathrm{C} 1 / \mathrm{O} 1 / \mathrm{C} 2)$ is twisted by $1.3(4)^{\circ}$, 
from that of the quinoline group, an increase of $3.8(2)^{\circ}$ in molecule A or $3.5(3)^{\circ}$ in molecule $\mathrm{B}$, respectively. These changes as well as changes in the $\mathrm{C} 11 / \mathrm{O} 2 / \mathrm{C} 1 / \mathrm{O} 1$ torsion angle from $-3.2(2)^{\circ}$ to $0.2(1)^{\circ}$ in molecule $\mathrm{A}$ or from $-2.9(3)^{\circ}$ to $0.2(1)^{\circ}$ in molecule B after the geometry optimization DFT calculation suggests that while the observed $\mathrm{C}---\mathrm{H} . . . \mathrm{O}$ and $\pi-\pi$ weak intermolecular interactions (Table 2) may influence somewhat the packing arrangement, only a high $\Delta E_{\text {config value representing energy differences }}$ between the optimized and experimental electronic transitions would be indicative of a significant departure from the ideal molecular conformation in the gas phase and, therefore, influence the crystal packing.

\subsection{Structural Study of (II): 2-Methoxyphenyl Quinoline-2-Carboxylate}

In (II), $\mathrm{C}_{17} \mathrm{H}_{13} \mathrm{NO}_{3}$, the dihedral angle between the mean planes of the quinoline and phenyl rings is $67.4(6)^{\circ}$ in the molecule (Figure 3a). The carboxylate group is twisted by $79.5(0)^{\circ}$ from the mean plane of the phenyl group. Bond lengths are in normal ranges [15] (Table 3). A weak C9---H9...O2 intermolecular interaction and weak $\pi-\pi$ stacking interactions (Figure $3 b$ ) between the two rings of the quinoline groups of nearby molecules are also observed (Table 4). No classical hydrogen bonds were observed.

After a DFT geometry optimization calculation he dihedral angle between the mean planes of the quinoline and 2-methoxyphenyl rings becomes $72.2(8)^{\circ}$, an increase of $4.8(2)^{\circ}$ (Figure $3 \mathrm{a}$ ). The mean plane of the carboxylate group $(\mathrm{O} 2 / \mathrm{C} 1 / \mathrm{O} 1 / \mathrm{C} 2)$ is twisted by $0.3(1)^{\circ}$, from that of the quinoline group, a decrease of $13.3(5)^{\circ}$. These changes as well as changes in the $\mathrm{C} 11 / \mathrm{O} 1 / \mathrm{C} 1 / \mathrm{O} 2$ torsion angle from $1.7(3)^{\circ}$ to $4.0(8)^{\circ}$ after the geometry optimization DFT calculation suggests that while the observed C---H...O and $\pi-\pi$ weak intermolecular interactions (Table 4) influence somewhat the packing arrangement, only

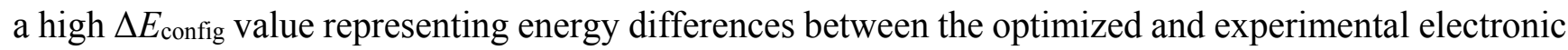
transitions would be indicative of a significant departure from the ideal molecular conformation in the gas phase and, therefore, influence the crystal packing.

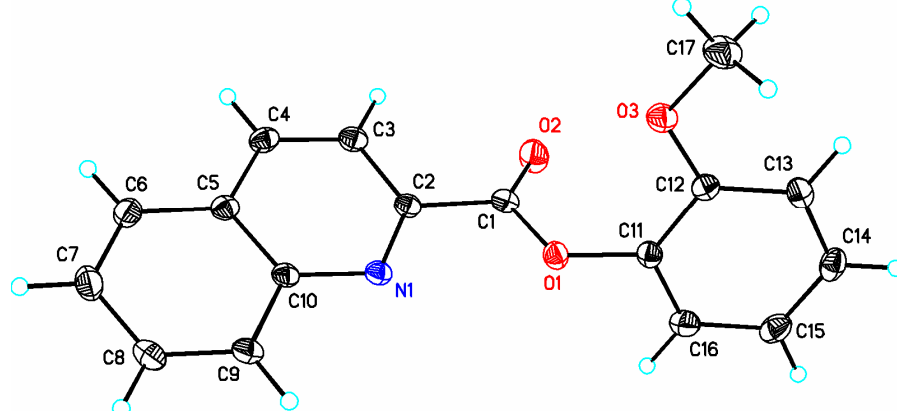

(a)

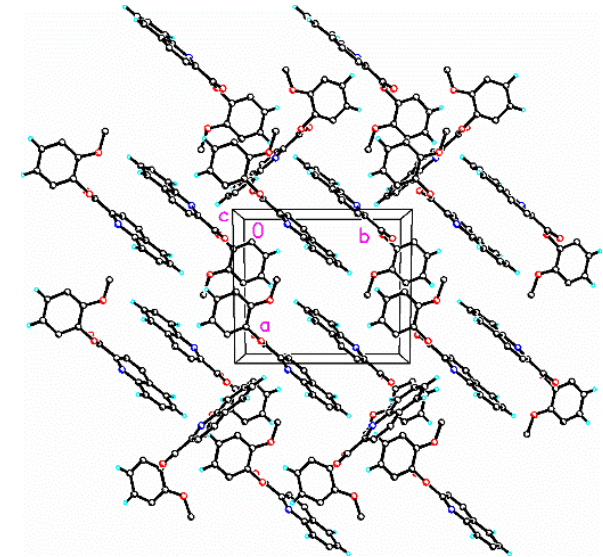

(b)

Figure 3. (a) Molecular structure of $\mathrm{C}_{17} \mathrm{H}_{13} \mathrm{NO}_{3}$, (II), showing the atom numbering scheme with 30\% probability ellipsoids; (b) Packing diagram for (II) viewed along the $c$ axis. $\mathrm{H}$ atoms not involved in hydrogen bonding have been removed for clarity. 
Table 3. Selected crystal and DFT* bond lengths $(\AA)$, bond angles $\left(^{\circ}\right)$, and torsion angles $\left(^{\circ}\right)$ for (II), $\mathrm{C}_{17} \mathrm{H}_{13} \mathrm{NO}_{3}$.

\begin{tabular}{cccccc}
\hline Atoms(II) & Distance(II) & DFT(II) & Atoms(II) & Distance(II) & DFT(II) \\
\hline O2-C1 & $1.1997(16)$ & $* 1.210$ & O1-C1 & $1.3494(15)$ & $* 1.358$ \\
O1-C11 & $1.4062(15)$ & $* 1.358$ & O3-C12 & $1.3626(16)$ & $* 1.360$ \\
O3-C17 & $1.4283(17)$ & $* 1.419$ & N1-C2 & $1.3183(16)$ & $* 1.320$ \\
N1-C10 & $1.3668(16)$ & $* 1.361$ & C1-C2 & $1.5021(18)$ & $* 1.504$ \\
C2-C3 & $1.4131(18)$ & $* 1.421$ & C3-C4 & $1.3596(19)$ & $* 1.373$ \\
C4-C5 & $1.4140(19)$ & $* 1.418$ & C5-C6 & $1.4178(19)$ & $* 1.419$ \\
C5-C10 & $1.4194(18)$ & $* 1.433$ & C6-C7 & $1.363(2)$ & $* 1.377$ \\
C7-C8 & $1.412(2)$ & $* 1.419$ & C8-C9 & $1.3660(2)$ & $* 1.376$ \\
C9-C10 & $1.4197(18)$ & $* 1.422$ & C11-C12 & $1.3950(18)$ & $* 1.407$ \\
C11-C16 & $1.3757(19)$ & $* 1.366$ & C12-C13 & $1.3930(18)$ & $* 1.398$ \\
C13-C14 & $1.387(2)$ & $* 1.399$ & C14-C15 & $1.379(2)$ & $* 1.392$ \\
\hline Atoms(II) & Angles(II) & DFT(2) & Atoms(II) & Angles(II) & DFT(II) \\
\hline C1-O1-C11 & $117.72(10)$ & $* 117.76$ & C2-N1-C10 & $117.26(11)$ & $* 117.91$ \\
O1-C1-O2 & $124.39(12)$ & $* 124.52$ & O1-C1-C2 & $111.51(10)$ & $* 112.25$ \\
O2-C1-C2 & $124.39(12)$ & $* 123.22$ & N1-C2-C1 & $117.83(11)$ & $* 118.95$ \\
N1-C2-C3 & $124.33(12)$ & $* 124.10$ & C3-C2-C1 & $117.82(11)$ & $* 116.95$ \\
C4-C3-C2 & $118.66(12)$ & $* 118.54$ & C4-C5-C6 & $123.26(12)$ & $* 123.56$ \\
C4-C5-C10 & $117.54(12)$ & $* 117.30$ & C6-C5-C1 & $119.18(12)$ & $* 119.14$ \\
C8-C9-C10 & $120.29(12)$ & $* 120.36$ & N1-C10-C5 & $122.69(11)$ & $* 122.58$ \\
N1-C10-C9 & $118.33(11)$ & $* 118.31$ & C12-C11-O1 & $119.51(11)$ & $* 119.76$ \\
C16-C11-O1 & $118.66(12)$ & $* 118.90$ & C2-N1-C10 & $117.26(11)$ & $* 117.91$ \\
\hline Atoms(II) & Torsion(II) & DFT(II) & Atoms(II) & Torsion(II) & DFT(II) \\
\hline O1-C1-C2-N1 & $-13.46(16)$ & $*-0.14$ & O1-C1-C2-C3 & $164.87(11)$ & $* 179.72$ \\
O2-C1-C2-N1 & $167.42(13)$ & $* 179.29$ & O2-C1-C2-C3 & $-14.25(19)$ & $*-0.56$ \\
O2-C1-O1-C11 & $1.74(19)$ & $* 4.08$ & O1-C11-C16-C15 & $-173.64(12)$ & $*-176.06$ \\
N1-C2-C3-C4 & $0.5(2)$ & $* 0.15$ & C1-O1-C11-C12 & $-104.49(14)$ & $*-72.68$ \\
C1-O1-C11-C16 & $-104.49(14)$ & $*-111.70$ & C2-N1-C10-C5 & $0.68(17)$ & $* 0.07$ \\
C2-N1-C10-C9 & $-177.81(11)$ & $*-180$ & C4-C5-C10-N1 & $0.30(18)$ & $* 0.11$ \\
C11-O1-C1-O2 & $1.74(19)$ & $* 4.08$ & C11-O1-C1-C2 & $1.74(19)$ & $* 176.78$ \\
\hline & & & & &
\end{tabular}

Table 4. Weak Intermolecular Interactions for (II) $\mathrm{C}_{17} \mathrm{H}_{13} \mathrm{NO}_{3},\left(\AA\right.$ and $\left.{ }^{\circ}\right)$.

\begin{tabular}{ccccc}
\hline D---H & $\boldsymbol{d}(\mathbf{D}---\mathbf{H})$ & $\boldsymbol{d}(\mathbf{H} . . . \mathrm{A})$ & $\boldsymbol{d}(\mathbf{D} \ldots \mathbf{A})$ & $<$ (DHA) \\
\hline $\mathrm{C} 9---\mathrm{H} 9 \ldots \mathrm{O} 22^{\# 1}$ & 0.95 & 2.61 & $3.4207(16)$ & 143.8 \\
$\mathrm{Cg} 1---\mathrm{Cg} 11^{\# 2}$ & - & - & - & $3.7719(7)$ \\
$\mathrm{Cg} 1---\mathrm{Cg} 2^{\# 2}$ & - & - & - & $3.6878(8)$ \\
\hline
\end{tabular}

Notes: Symmetry transformations used to generate equivalent atoms: ${ }^{\# 1}-x,-1 / 2+y,-1 / 2-z ;{ }^{\# 2}-x, 1-y$, $1-z ; \mathrm{Cg} 1=\mathrm{N} 1 / \mathrm{C} 2 / \mathrm{C} 3 / \mathrm{C} 4 / \mathrm{C} 5 / \mathrm{C} 10 ; \mathrm{Cg} 2=\mathrm{C} 5-\mathrm{C} 10$.

\subsection{Computational Details}

A density functional theory (DFT) molecular orbital calculation (WebMoPro) [16] with the GAUSSIAN-03 program package [17] employing the B3LYP (Becke three parameter Lee-Yang-Parr) exchange correlation functional, which combines the hybrid exchange functional of Becke $[18,19]$ with 
the gradient correlation functional of Lee, Yang and Parr [19] and the 6-31 G(d) basis set [20] was performed on each of the two molecules (I and II) studied. No solvent corrections were made with these calculations. Starting geometries were taken from X-ray refinement data. The optimized results in the free molecule or gas phase state are, therefore, compared to those in the crystalline state. Experimentally determined oscillator strengths $(f)$ were determined by use of the equation relating them to the molar decadic absorption coefficient $(e)\left(f=4.32 \times 10^{-9} e_{\max } \cdot \Delta x_{1 / 2}\right)$ [21,22]. The molar decadic absorption coefficient measures the intensity of the optical absorption at a given wavelength. Deconvolution of the spectra to obtain the $e_{\max }$ and $\Delta x_{1 / 2}$ values was carried out by the IGOR program [23]. Discrepancies between the experimental and calculated band centers and band intensities exist. However, this does not prohibit us from making informed decisions on the observations since it is generally known that DFT often underestimates HOMO-LUMO gaps, thereby having a tendency to give excitations far too low in energy. All calculations were performed on a workstation PC using default convergence criteria.

\subsection{Theoretical Density Functional Theory (DFT) Calculations for (I) and (II)}

From a DFT molecular orbital calculation for each molecule (I) and (II), surface plots for the two highest occupied molecular orbital (HOMO and HOMO-1) and four lowest unoccupied molecular orbitals (LUMO, LUMO+1, LUMO+2, $\mathrm{LUMO}+3$ ) are displayed to provide visual evidence of the molecular orbitals involved in the spectroscopic electronic energy transitions examined. Based on correlation of the energies of these HOMO-LUMO frontier surfaces to the UV-Vis absorption spectra (Table 5), electronic excitation transition predications are suggested.

Table 5. Experimental and Calculated Energy of Molecular Orbitals of (I) and Associated Transitions.

\begin{tabular}{ccccc}
\hline$\lambda_{\max }(\mathbf{n m} / \mathbf{e V})$ & Experimental (MO Contributions) & $\boldsymbol{f}^{*}$ & $\boldsymbol{\lambda}_{\max }(\mathbf{n m} / \mathbf{e V})$ & Calculated (MO Contributions) \\
\hline $322 / 3.85$ & HOMO $\rightarrow$ LUMO & 0.87 & $267 / 4.64$ & HOMO $\rightarrow$ LUMO \\
$322 / 3.85$ & HOMO $-1 \rightarrow$ LUMO & 0.87 & $261 / 4.75$ & HOMO $-1 \rightarrow$ LUMO \\
$322 / 3.85$ & HOMO $\rightarrow$ LUMO+1 & 0.87 & $224 / 5.54$ & HOMO $\rightarrow$ LUMO+1 \\
$322 / 3.85$ & HOMO $-1 \rightarrow$ LUMO+1 & 0.87 & $219 / 5.66$ & HOMO $-1 \rightarrow$ LUMO+1 \\
$322 / 3.85$ & HOMO $\rightarrow$ LUMO+2 & 0.87 & $193 / 6.42$ & HOMO $\rightarrow$ LUMO+2 \\
$322 / 3.85$ & HOMO $\rightarrow$ LUMO+3 & 0.87 & $190 / 6.53$ & HOMO $-1 \rightarrow$ LUMO+2 \\
$322 / 3.85$ & HOMO $-1 \rightarrow$ LUMO+2 & 0.87 & $189 / 6.56$ & HOMO $\rightarrow$ LUMO +3 \\
\hline
\end{tabular}

Notes: $f^{*}, f=4.32 \times 10^{-9} \varepsilon_{\max } \cdot \Delta \omega 1 / 2$ Frontier molecular orbitals from output in B3LYP G(d) calculation.

\subsection{DFT Frontier Molecular Orbitals for (I)}

Calculated molecular orbital energies $(\mathrm{eV})$ for the surfaces of the frontier molecular orbitals for (I) are shown in Figure 4a and Table 5. In HOMO-1 and HOMO, electronic clouds are distributed primarily on the phenyl and quinoline groups, respectively. In LUMO, LUMO+1, electronic clouds are delocalized primarily on the quinoline ring while In LUMO+2 and LUMO+3 electron clouds are delocalized on the phenyl ring. The observed experimental absorption spectrum shows one intense band envelope at $\lambda_{\max }=322 \mathrm{~nm}$. Electronic transitions are generally paired between the various molecular orbitals of the ground and excited states corresponding to this single band envelope as indicated in Table 5. Therefore, the absorption band envelope at $322 \mathrm{~nm}$ is assigned to overlapping contributions from each of 
$\mathrm{HOMO} \rightarrow \mathrm{LOMO}, \mathrm{HOMO}-1 \rightarrow \mathrm{LUMO}, \mathrm{HOMO} \rightarrow \mathrm{LOMO}+1, \mathrm{HOMO}-1 \rightarrow \mathrm{LUMO}+1, \mathrm{HOMO} \rightarrow \mathrm{LUMO}+2$, $\mathrm{HOMO}-1 \rightarrow \mathrm{LUMO}+2$ and $\mathrm{HOMO} \rightarrow \mathrm{LUMO}+3$, respectively. The energy differences $\left(\Delta E_{\text {config }}\right)$ between the optimized and experimental electronic transitions for (I) are 0.79, 0.90, 1.69, 1.81, 2.57, 2.86 and $2.71 \mathrm{eV}$, respectively, that are associated with the broad band envelope at $322 \mathrm{~nm}$. However, this comparison while suggestive of some interaction, is inconclusive in relation to an extension of their effects on crystal packing.

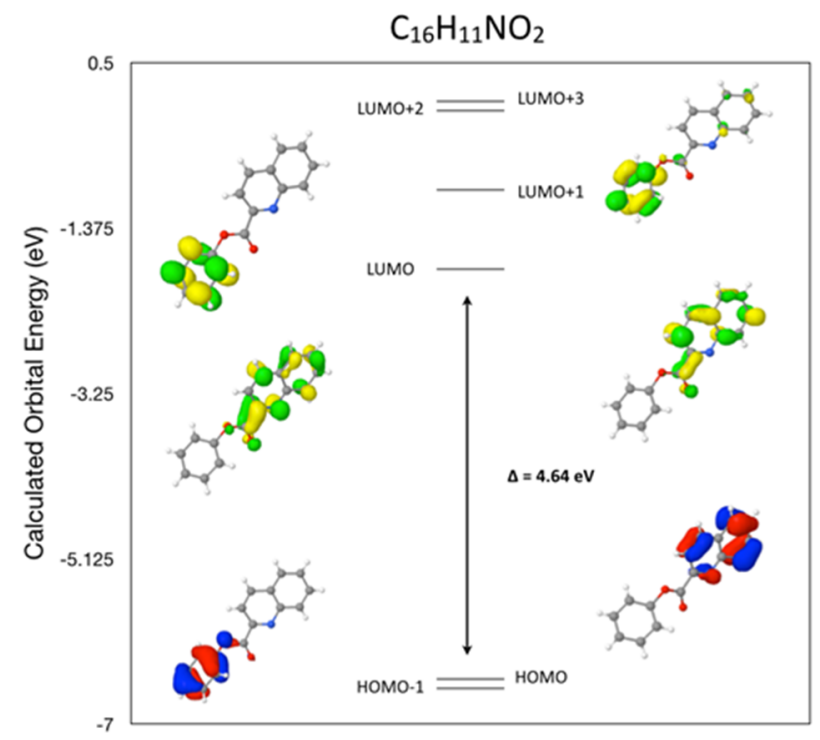

(a)

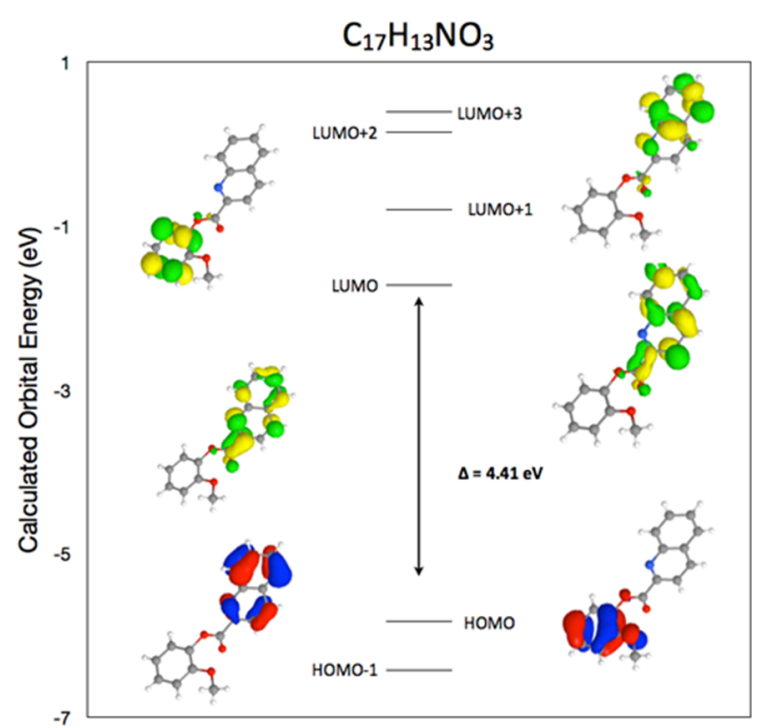

(b)

Figure 4. Calculated frontier molecular orbitals for (I) and (II). (a) $\mathrm{C}_{16} \mathrm{H}_{11} \mathrm{NO}_{2}$ (I); (b) $\mathrm{C}_{17} \mathrm{H}_{13} \mathrm{NO}_{3}$ (II).

\subsection{DFT Frontier Molecular Orbitals for (II)}

Calculated molecular orbital energies (eV) for the surfaces of the frontier molecular orbitals for (II) are shown in Figure $4 \mathrm{~b}$ and Table 6. In HOMO-1 and HOMO, electronic clouds are distributed primarily on the quinoline and methoxyphenyl groups, respectively. In LUMO, LUMO+1 and LUMO+3 electronic clouds are delocalized primarily on the quinoline ring while in $\mathrm{LUMO}+2$ electron clouds are delocalized on the 2-methoxyphenyl ring. The observed experimental absorption spectrum shows one intense band envelope at $\lambda_{\max }=254 \mathrm{~nm}$ and a second less intense band envelope at $319 \mathrm{~nm}$. Electronic transitions are generally paired between the various molecular orbitals of the ground and excited states corresponding to these two band envelopes as indicated in Table 6. Therefore, the absorption band envelope at $254 \mathrm{~nm}$ is assigned to overlapping contributions from each of $\mathrm{HOMO} \rightarrow \mathrm{LOMO}, \mathrm{HOMO}-1 \rightarrow \mathrm{LUMO}$ and $\mathrm{HOMO} \rightarrow \mathrm{LOMO}+1$ while the band envelope at $319 \mathrm{~nm}$ is assigned to $\mathrm{HOMO}-1 \rightarrow \mathrm{LUMO}+1$, $\mathrm{HOMO} \rightarrow \mathrm{LUMO}+2, \quad \mathrm{HOMO}-1 \rightarrow \mathrm{LUMO}+2$ and $\mathrm{HOMO} \rightarrow \mathrm{LUMO}+3$, respectively. The energy differences ( $\Delta E_{\text {config }}$ ) between the optimized and experimental electronic transitions for (II) are $0.23,0.83$ and $1.16 \mathrm{eV}$ for the band envelope at $319 \mathrm{~nm}$ and $0.76,1.11,1.35$ and $1.68 \mathrm{eV}$ associated with the band envelope at $254 \mathrm{~nm}$, respectively. As with (I), this comparison while suggestive of some interaction, it is also inconclusive in relation to an extension of their effects on crystal packing. 
Table 6. Experimental and calculated energy of molecular orbitals of (II) and associated transitions.

\begin{tabular}{ccccc}
\hline $\boldsymbol{\lambda}_{\max }(\mathbf{n m} / \mathbf{e V})$ & Experimental (MO Contributions) & $\boldsymbol{f}^{*}$ & $\boldsymbol{\lambda}_{\max }(\mathbf{n m} / \mathbf{e V})$ & Calculated (MO Contributions) \\
\hline $319 / 3.88$ & $\mathrm{HOMO} \rightarrow \mathrm{LUMO}$ & 1.97 & $302 / 4.11$ & $\mathrm{HOMO} \rightarrow \mathrm{LUMO}$ \\
$319 / 3.88$ & $\mathrm{HOMO}-1 \rightarrow \mathrm{LUMO}$ & 1.97 & $263 / 4.71$ & $\mathrm{HOMO}-1 \rightarrow \mathrm{LUMO}$ \\
$319 / 3.88$ & $\mathrm{HOMO} \rightarrow \mathrm{LUMO}+1$ & 1.97 & $246 / 5.04$ & $\mathrm{HOMO} \rightarrow \mathrm{LUMO}+1$ \\
$254 / 4.88$ & $\mathrm{HOMO}-1 \rightarrow \mathrm{LUMO}+1$ & 0.72 & $220 / 5.64$ & $\mathrm{HOMO}-1 \rightarrow \mathrm{LUMO}+1$ \\
$254 / 4.88$ & $\mathrm{HOMO} \rightarrow \mathrm{LUMO}+2$ & 0.72 & $207 / 5.99$ & $\mathrm{HOMO} \rightarrow \mathrm{LUMO}+2$ \\
$254 / 4.88$ & $\mathrm{HOMO} \rightarrow \mathrm{LUMO}+3$ & 0.72 & $199 / 6.23$ & $\mathrm{HOMO} \rightarrow \mathrm{LUMO}+3$ \\
$254 / 4.88$ & $\mathrm{HOMO}-1 \rightarrow \mathrm{LUMO}+2$ & 0.72 & $189 / 6.56$ & $\mathrm{HOMO}-1 \rightarrow \mathrm{LUMO}+2$ \\
\hline
\end{tabular}

Notes: $f^{*}, f=4.32 \times 10^{-9} \varepsilon_{\max } \cdot \Delta \omega 1 / 2$ Frontier molecular orbitals from output in B3LYP G(d) calculation.

\subsection{Comparison of the Frontier Molecular Orbitals from Six Related Quinoline-2-Carboxylate} Derivatives to the Title Compounds

A display of the DFT frontier molecular orbitals from six similar and related quinoline-2-carboxylate derivatives previously published in this laboratory is shown in Figure 5a-f.

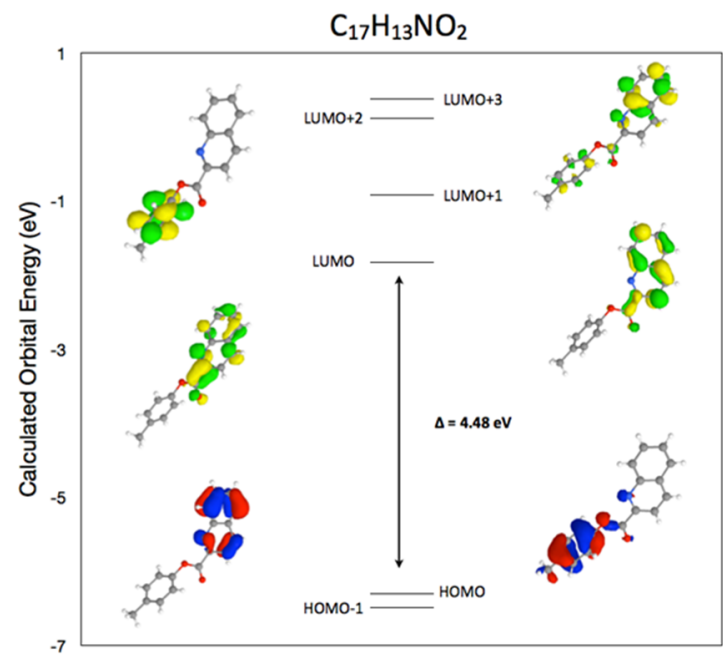<smiles>Cc1ccc(OC(=O)c2ccc3ccccc3n2)cc1</smiles>

(a)

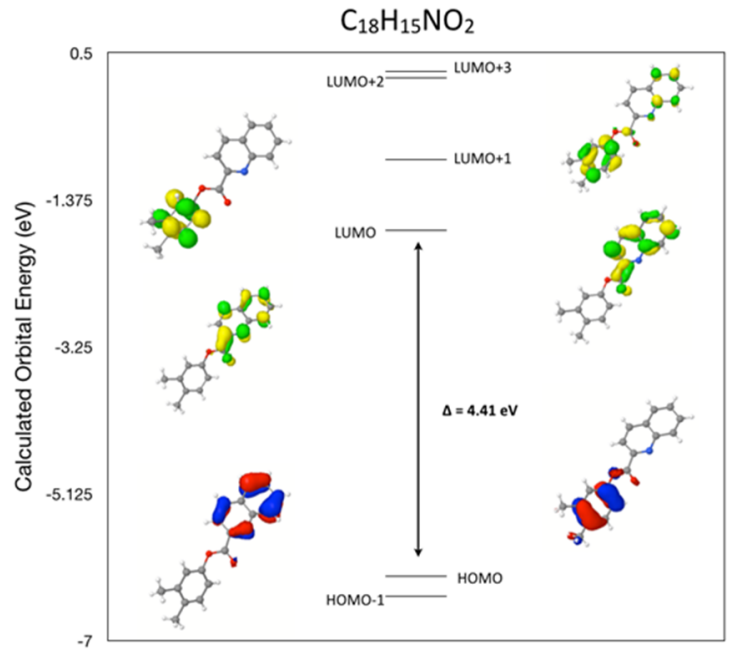<smiles>Cc1ccc(OC(=O)c2ccc3ccccc3n2)cc1C</smiles>

(b)

Figure 5. Cont. 


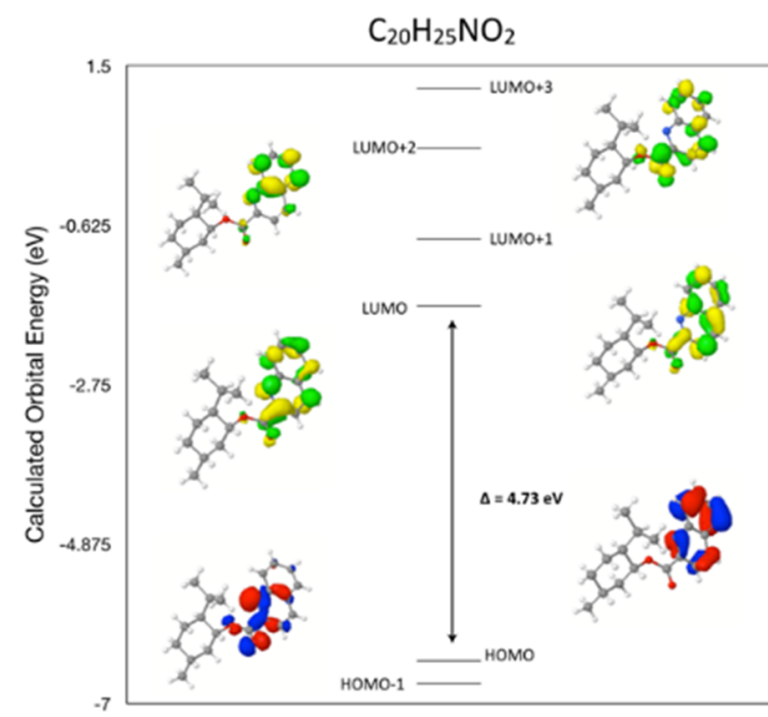

(c)

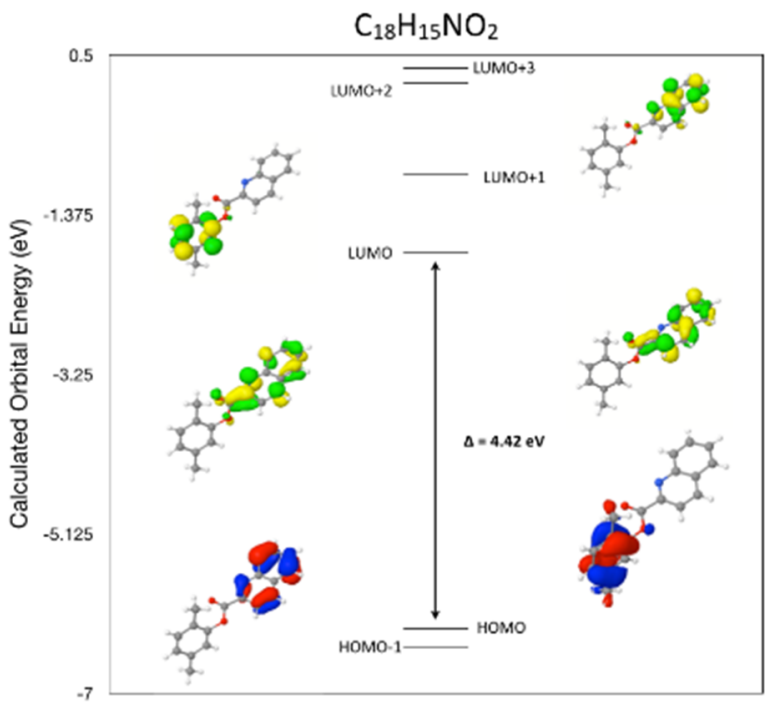<smiles>Cc1ccc(C)c(OC(=O)c2ccc3ccccc3n2)c1</smiles>

(d)

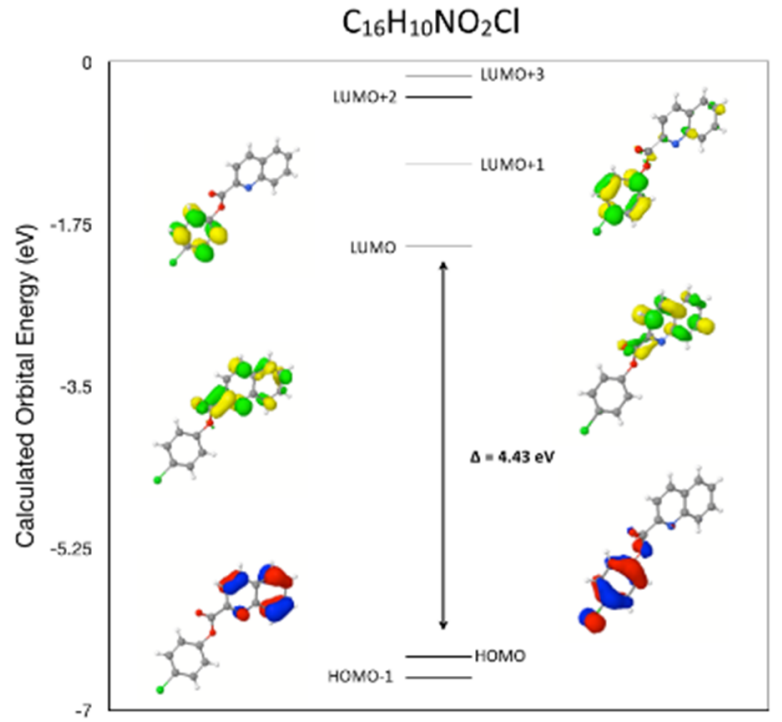

(e)

Figure 5. Cont. 


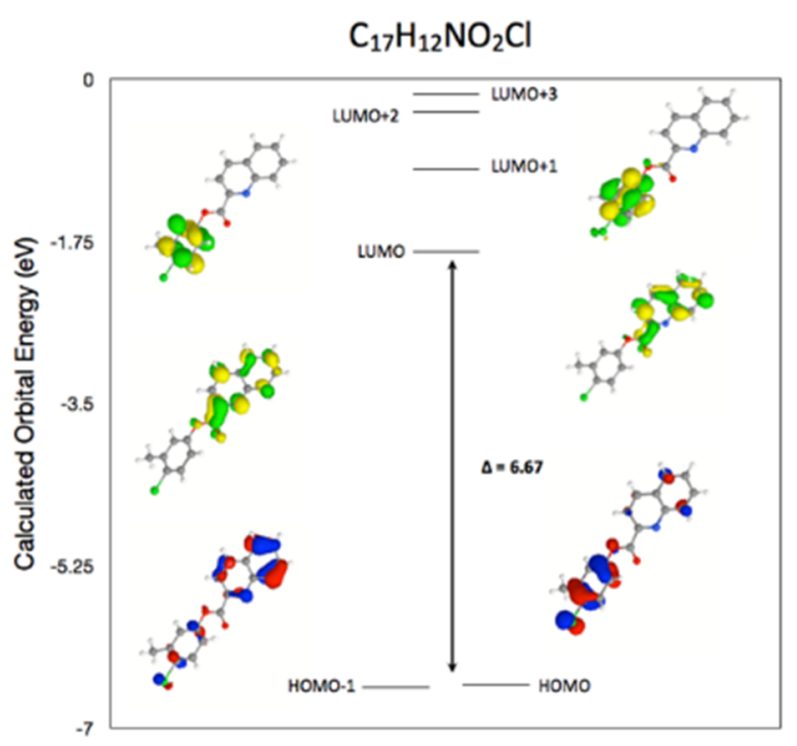<smiles>Cc1cc(OC(=O)c2ccc3ccccc3n2)ccc1Cl</smiles>

(f)

Figure 5. Calculated frontier molecular orbitals for compounds III-VIII. (a) calculated frontier molecular orbitals for $\mathrm{C}_{17} \mathrm{H}_{13} \mathrm{NO}_{2}$ (III) (Reprinted with permission from [8], Copyright 2012 Acta Crystallographica Section E); (b) calculated frontier molecular orbitals for $\mathrm{C}_{18} \mathrm{H}_{15} \mathrm{NO}_{2}$ (IV) (Reprinted with permission from [11]. Copyright 2014 Acta Crystallographica Section E); (c) calculated frontier molecular orbitals for $\mathrm{C}_{20} \mathrm{H}_{25} \mathrm{NO}_{2}$ (V) (Reprinted with permission from [12], Copyright 2014 Acta Crystallographica Section E); (d) calculated frontier molecular orbitals for $\mathrm{C}_{18} \mathrm{H}_{15} \mathrm{NO}_{2}$ (VI) (Reprinted with permission from [13], Copyright 2013 Acta Crystallographica Section E); (e) calculated frontier molecular orbitals for $\mathrm{C}_{16} \mathrm{H}_{10} \mathrm{NO}_{2} \mathrm{Cl}$ (VII) (Reprinted with permission from [10], Copyright 2013 Acta Crystallographica Section E); (f) calculated frontier molecular orbitals for $\mathrm{C}_{17} \mathrm{H}_{12} \mathrm{NO}_{2} \mathrm{Cl}$ (VIII) (Reprinted with permission from [9]. Copyright 2013 Acta Crystallographica Section E).

The absorption spectra for each of the six molecules shown above display two intense absorption maxima with $\lambda_{\max }$ between $251-253 \mathrm{~nm}$ and 316-320 $\mathrm{nm}$ indicating slight shifts in band maxima being related most likely to the various substituted groups on the phenyl moiety. The oscillator strengths of each of these two band envelopes in (III-VIII) are also in similar ranges as recorded for molecules (I) and (II) (see Table S1-S6 for DFT HOMO-LUMO assignments of molecules III-VIII). From the DFT calculated frontier surface molecular orbitals for compounds (III-VIII) in Figure 5, it is therefore suggested that each of these molecules can be assigned to similar transitions within the band envelopes as described for molecules (I) and (II) providing further support for these collective HOMO-LUMO assignments in the title molecules. 


\section{Experimental Section}

\subsection{Synthesis of Phenyl Quinoline-2-Carboxylate and 2-Methoxyphenyl Quinoline-2-Carboxylate}

The two quinoline-2-carboxylates (I) and (II) were prepared by the following method (Scheme 1). To a mixture of quinaldic acid (1.73 g, 10 mmole) and o-methoxyphenol (1.24 g, 10 mmole) (I) or phenol (0.9 g, 10 mmole) (II) in a round-bottomed flask fitted with a reflux condenser and a drying tube, ( $0.150 \mathrm{~g}, 10 \mathrm{mmole})$ of phosphorous oxychloride was added. The mixture was heated with occasional swirling maintaining the temperature at 348-353 K. At the end of eight hours (I) or six hours (II) the reaction mixture was poured into a solution of $2 \mathrm{~g}$ of sodium bicarbonate in $25 \mathrm{~mL}$ of water. The precipitated esters were collected on a filter and washed with water. The yield of crude, air dried 2-methoxyphenyl quinoline-2-carboxylate (I) was (80\%-90\%) and air dried phenyl quinoline-2-carboxylate (II) was (55\%-60\%). X-ray quality crystals of both (I) and (II) were obtained by recrystallization from absolute ethanol.<smiles>O=C(O)c1ccc2ccccc2n1</smiles><smiles>O=C(Oc1ccccc1)c1ccc2ccc(C(F)(F)F)cc2n1</smiles>

(I)<smiles>COc1ccccc1O</smiles><smiles>COc1ccccc1OC(=O)c1ccc2ccc(CC(C)([O])O)cc2n1</smiles>

(II)

Scheme 1. The synthesis of $\mathrm{C}_{16} \mathrm{H}_{11} \mathrm{NO}_{2}$ (I) and $\mathrm{C}_{17} \mathrm{H}_{13} \mathrm{NO}_{3}$ (II).

The melting points were determined on SELACO melting point in open capillary tubes and are uncorrected. Reactions were monitored by Thin-layer chromatography (TLC) using pre-coated sheets of silica gel G/UV-254 of $0.25 \mathrm{~mm}$ thickness (Merck 60F 254 ) using UV light for visualization. All the solvents and reagents used for the synthesis were of analytical grade and procured from Sigma Chemical Co. (St. Louis, MO, USA). NMR spectra $\left({ }^{1} \mathrm{H}\right.$ and ${ }^{13} \mathrm{C}$ ) for the compound was recorded on a $500 \mathrm{MHz}$ NMR Spectrometer (Bruker advance, Reinstetten, Germany) using deuteriated DMSO as the solvent. The chemical shift values (ppm) and coupling constants $(\mathrm{J})$ are given in $\delta$ and $\mathrm{Hz}$ respectively. Mass spectral analysis was carried out in the ESI positive mode using HRMS mass spectrometer (Waters Q-Tof Utima, Manchester, UK). OD of the samples was measured using UV/Vis spectrometer, UV-1800 Shimadzu, Tokyo, Japan. 
Phenyl quinoline-2-carboxylate (I): $\mathbf{C}_{16} \mathbf{H}_{11} \mathbf{N O}_{2} ; 363 \mathrm{~K} ;{ }^{1} \mathrm{HNMR}(500 \mathrm{MHz}, \mathrm{DMSO}) \delta 8.6(1 \mathrm{H}, \mathrm{d}$, $J=8.5 \mathrm{~Hz}), 8.35(1 \mathrm{H}, \mathrm{d}, J=8.5 \mathrm{~Hz}), 8.30(1 \mathrm{H}, \mathrm{d}, J=8.5 \mathrm{~Hz}), 8.09(1 \mathrm{H}, \mathrm{d}, J=8.15 \mathrm{~Hz}), 7.92(1 \mathrm{H}, \mathrm{dd}$, $\left.J_{1}=8.38 \mathrm{~Hz}, J_{2}=6.91 \mathrm{~Hz}, J_{3}=1.3 \mathrm{~Hz}\right), 7.79\left(1 \mathrm{H}, \mathrm{ddd}, J_{1}=8.10 \mathrm{~Hz}, J_{2}=6.91 \mathrm{~Hz}, J_{3}=1 \mathrm{~Hz}\right), 7.52(1 \mathrm{H}$, $\mathrm{t}, J=7.65 \mathrm{~Hz}, 8.26 \mathrm{~Hz}) .{ }^{13} \mathrm{CNMR}(125 \mathrm{MHz}, \mathrm{DMSO}) \delta=46.768,47.449,47.789,120.586,121.037$, $125.646,127.405,128.602$, 129.457, 130.361, 137.824, 146.798, 146.989, 150.801, 163.314. IR $\left(\mathrm{KBr}, v_{\max } / \mathrm{cm}^{-1}\right)$ 3054, 1757, 1588, 1485, 1456, 1196, 1132, 1094. HRMS: Mass (ESI): [M + 1] for $\mathrm{C}_{16} \mathrm{H}_{11} \mathrm{NO}_{2}$, Calculated: 249.08; Found: 249.75.

2-Methoxyphenyl quinoline-2-carboxylate (II): $\mathbf{C}_{\mathbf{1 7}} \mathbf{H}_{\mathbf{1 3}} \mathbf{N O}_{\mathbf{3}} ; 395 \mathrm{~K} ;{ }^{1} \mathrm{HNMR}$ (500 MHz, DMSO) $\delta=8.65(1 \mathrm{H}, \mathrm{d}, J=8.7 \mathrm{~Hz}), 8.36(1 \mathrm{H}, \mathrm{d}, J=8.5 \mathrm{~Hz}), 8.32(1 \mathrm{H}, \mathrm{d}, J=8.5 \mathrm{~Hz}), 8.13(1 \mathrm{H}, \mathrm{d}, J=8.21 \mathrm{~Hz})$, $7.95\left(1 \mathrm{H}, \mathrm{ddd}, J_{1}=8.2 \mathrm{~Hz}, J_{2}=6.78 \mathrm{~Hz}, J_{3}=1 \mathrm{~Hz}\right), 7.82(1 \mathrm{H}, \mathrm{t}, J=7.82 \mathrm{~Hz}, 7.23 \mathrm{~Hz}), 7.37(1 \mathrm{H}, \mathrm{dt}$, $\left.J_{1}=8.3 \mathrm{~Hz}, J_{2}=1.31 \mathrm{~Hz}\right), 7.31\left(1 \mathrm{H}, \mathrm{dd}, J_{1}=7.8 \mathrm{~Hz}, J_{2}=1.37 \mathrm{~Hz}\right), 7.10\left(1 \mathrm{H}, \mathrm{dt}, J_{1}=7.55 \mathrm{~Hz}\right.$, $\left.J_{2}=1.04 \mathrm{~Hz}\right), 3.88(3 \mathrm{H}, \mathrm{s}) .{ }^{13} \mathrm{CNMR}(125 \mathrm{MHz}, \mathrm{DMSO}) \delta=56.264,113.739,121.692,122.071,123.543$, 128.287, 128.871, 130.018, 130.527, 130.700, 131.773, 139.134, 141.003, 147.994, 148.371, 152.303, 164.134. IR (KBr, $\left.v_{\max } / \mathrm{cm}^{-1}\right)$ 3055.1, 3009.7, 2926, 2835, 1736, 1606,1501,1463,1440, 1262, 1198 , 1169, 1120, 1084, 1045, 842,777, 754. HRMS: Mass (ESI): [M + 1] for $\mathrm{C}_{17} \mathrm{H}_{13} \mathrm{NO}_{3}$, Calculated: 279.09; Found: 279.78 .

\subsection{Data Collection and Refinement}

Crystallographic data for both (I) and (II) were collected with an Agilent Gemini R EOS CCD area detector using CrysAlisPro software [24] and graphite-monochromated $\mathrm{Cu}-\mathrm{K} \alpha \lambda=1.54178 \AA$ ) radiation at 173(2) K. Using Olex2 [25], the structures were solved by Superflip [26] using Charge Flipping and all of the non-hydrogen atoms were refined anisotropically by full-matrix least-squares on $\mathrm{F}^{2}$ using SHELX2014 [27]. In [I \& II] the hydrogen atoms were placed in their calculated positions and included in the refinement using the riding model with $\mathrm{C}-\mathrm{H}$ lengths of $0.95 \AA(\mathrm{CH}), 0.99 \AA\left(\mathrm{CH}_{2}\right)$ or $0.98 \AA$ $\left(\mathrm{CH}_{3}\right)$. The isotropic displacement parameters for these atoms were set to $1.2\left(\mathrm{CH}, \mathrm{CH}_{2}\right)$, or $1.5\left(\mathrm{CH}_{3}\right)$, times $U_{\text {eq }}$ of the parent atom. Idealized $\mathrm{Me}$ groups were refined as rotating groups in (II) [C17(H17A,H17B,H17C)]. An absorption correction was performed on each structure using CrysAlis $R E D$ [24] and both structures were checked using PLATON [28].

Crystal data for $(\mathbf{I})$ : yellow needle, $0.14 \times 0.12 \times 0.06 \mathrm{~mm}, \mathrm{C}_{16} \mathrm{H}_{11} \mathrm{NO}_{2}, M_{\mathrm{r}}=249.08$, monoclinic $P 2{ }_{1} / c, a=14.7910(3) \AA ; b=5.76446(12) \AA ; c=28.4012(6) \AA ; \beta=99.043(2)^{\circ}$ and $V=2391.45(9) \AA^{3}$; $Z=8, F(000)=695, T=123(2) \mathrm{K}, \rho_{\text {calc }}=1.258 \mathrm{~g} \cdot \mathrm{cm}^{-3}, \mu=0.652 \mathrm{~mm}^{-1}, 13890$ reflections measured $\left(-18 \leq h \leq 14,-6 \leq k \leq 6,-34 \leq l \leq 34 ; 3.15 \leq \theta \leq 71.46^{\circ}\right), R_{\text {int }}=0.0373,4561$ merged reflections, $\left.G O F=1.080, R(F)[I \geq 2 \sigma(I)]=0.0630, w R\left(F^{2}\right)=0.1857, w=1 / \sigma^{2}\left(F_{0}^{2}\right)+0.0541 P^{2}\right]$, where $P=\left(F_{\mathrm{o}}{ }^{2}+2 F_{\mathrm{c}}{ }^{2}\right) / 3$, min./max. $\Delta \rho=-0.30,+0.31 \mathrm{e} \AA^{-3}$. The quoted $w R\left(F^{2}\right)$ values are for all data or give the applied sigma limit for observed data. Cambridge Database deposition number: CSD-1039091.

Crystal data for $(\mathbf{I I})$ : colorless needle, $0.22 \times 0.18 \times 0.08 \mathrm{~mm}, \mathrm{C}_{17} \mathrm{H}_{13} \mathrm{NO}_{3}, M_{\mathrm{r}}=279.09$, monoclinic $P 21 / n, a=9.6095(3) \AA ; b=10.8040(3) \AA ; c=13.2427(4) \AA ; \beta=102.012(3)^{\circ}$; and $V=1344.76(7) \AA^{3}$; $Z=4, F(000)=597, T=173(2) \mathrm{K}, \rho_{\text {calc }}=1.343 \mathrm{~g} \cdot \mathrm{cm}^{-3}, \mu=0.696 \mathrm{~mm}^{-1}, 8310$ reflections measured $(-11 \leq h \leq 11,-9 \leq k \leq 13,-15 \leq l \leq 16 ; 5.21 \leq \theta \leq 71.29), R_{\text {int }}=0.0326,2582$ merged reflections, $\left.G O F=0.973, R(F)[\mathrm{I} \geq 2 \sigma(\mathrm{I})]=0.0383, w R\left(F^{2}\right)=0.0979, w=1 / \sigma^{2}\left(F_{\mathrm{o}}{ }^{2}\right)+0.0541 P^{2}\right]$, where 
$P=\left(F_{\mathrm{o}}{ }^{2}+2{F_{\mathrm{c}}}^{2}\right) / 3$, min./max. $\Delta \rho=-0.18,+0.26 e \AA^{-3}$. The quoted $w R\left(F^{2}\right)$ values are for all data or give the applied sigma limit for observed data. Cambridge Database deposition number: CSD-1039092.

\section{Conclusions}

The crystal and molecular structure of two new derivatives of quinolone-2-carboxylic acid have been determined along with the frontier molecular orbitals of each compound displayed through density function theory (DFT-B3LYP 6-31G(d)), geometry optimization and molecular orbital calculations. Correlation between the calculated molecular orbital energies $(\mathrm{eV})$ for the surfaces of the frontier molecular orbitals to the electronic excitation transitions from the absorption spectrum of each compound has been determined. In each compound, the DFT molecular orbital calculation, supported by a geometry optimization calculation confirmed that the excitation energies of the surfaces of the frontier molecular orbitals from the HOMO-1 and HOMO to LUMO, LUMO+1, LUMO+2 and LUMO +3 electronic excitations closely match the $\lambda_{\max }$ values of the absorption spectra in overlapping contributions from three to five of these excitations within each band envelope. In the crystal structures of both (I) and (II) no classical hydrogen bonds were observed. In (I) weak C---H...O intermolecular interactions and $\pi-\pi$ stacking interactions between the two rings of the quinoline group and carboxyl oxygen atoms of nearby molecules are present, while in (II), weak C---H...O and $\pi-\pi$ stacking interactions between the two rings of the quinoline groups of nearby molecules are observed. While the energy differences ( $\left.\Delta E_{\text {config }}\right)$ between the optimized and experimental electronic transitions for (I) and (II) associated with the band envelopes for each structure are suggestive of some interaction, it is inconclusive in relation to an extension of their effects on crystal packing.

\section{Acknowledgments}

Edakot Fazal thanks the Central Food Technological Research Institute, Mysore and Yuvaraja's College, University of Mysore for providing research facilities. Edakot Fazal is grateful to Javagal Rangaswamy Manjunatha, Spice and Flavor Science Department, Council of Scientific and Industrial Research-Central Food Technological Research Institute for Nuclear Magnetic Resonance spectra. Jerry P. Jasinski acknowledges the NSF-MRI program (Grant No. CHE-1039027) for funds to purchase the X-ray diffractometer.

\section{Author Contributions}

Edakot Fazal designed the experiments and synthesized the compounds; Jerry P. Jasinski performed the DFT calculations and wrote the paper; Brian J. Anderson collected X-ray data for the compounds; Manpreet Kaur solved the X-ray structures and interpreted the crystallographic results; Subban Nagarajan contributed reagents/materials/analysis tools for the project and Belgur Satyanarayana Sudha analyzed and interpreted the NMR, Mass Spec and IR data.

\section{Conflicts of Interest}

The authors declare no conflict of interest. 


\section{References}

1. Morimoto, Y.; Matsuda, F.; Shirahama, H. Total Synthesis of $( \pm)$-Virantmycin and Determination of Its Stereochemistry. Synlett 1991, 3, 202-203.

2. Michael, J.P. Quinoline, Quinazoline and Acridone Alkaloids. Nat. Prod. Rep. 2008, 25, 166-187.

3. Padwa, A.; Brodney, M.A.; Liu, B.; Satake, K.; Wu, T. Cycloaddition Approach toward the Synthesis of Substituted Indolines and Tetrahydroquinolines. J. Org. Chem. 1999, 64, 3595-3607.

4. Markees, D.G.; Dewey, V.C.; Kidder, G.W. Antiprotozoal 4-aryloxy-2-aminoquinolines and related compounds. J. Med. Chem. 1970, 13, 324-326.

5. Campbell, S.F.; Hardstone, J.D.; Palmer, M.J. 2,4-Diamino-6,7-Dimethoxyquinoline Derivatives as $\alpha_{1}$-Adrinoceptor Antagonists and Antihypertensive Agents. J. Med. Chem. 1988, 31, 1031-1035.

6. Musiol, R.; Magdziarz, T.; Kurczyk. A. Quinoline Scaffold as a Privileged Substructure in Antimicrobial Drugs. In Science against Microbial Pathogens: Communicating Current Research and Technological Advances; Formatex Research Center: Badajoz, Spain, 2011.

7. Solomon, V.R.; Lee, H. Quinoline as a Privileged Scaffold in Cancer Drug Discovery. Curr. Med. Chem. 2011, 18, 1488-1508.

8. Fazal, E.; Jasinski, J.P.; Krauss, S.T.; Sudha, B.S.; Yathirajan, H.S. 4-Methylphenyl quinoline-2carboxylate. Acta Cryst. 2012, E68, o3231-03232.

9. Fazal, E.; Kaur, M.; Sudha, B.S.; Nagarajan, S.; Jasinski, J.P. 4-Chloro-3-methylphenyl quinoline-2-carboxylate. Acta Cryst. 2013, E69, o1842-o1843.

10. Fazal, E.; Kaur, M.; Sudha, B.S.; Nagarajan, S.; Jasinski, J.P. 4-Chlorophenyl quinoline-2-carboxylate. Acta Cryst. 2013, E69, doi:10.1107/S1600536813032.

11. Fazal, E.; Kaur, M.; Sudha, B.S.; Nagarajan, S.; Jasinski, J.P. 3,4-Dimethylphenyl quinoline-2carboxylate. Acta Cryst. 2014, E69, o1853-o1854.

12. Fazal, E.; Kaur, M.; Sudha, B.S.; Nagarajan, S.; Jasinski, J.P. 2,5-Dimethylphenyl quinoline-2carboxylate. Acta Cryst. 2014, E70, doi:10.1107/S160053681400052X.

13. Fazal, E.; Jasinski, J.P.; Anderson, B.J.; Sudha, B.S.; Nagarajan, S. 2-Isopropyl-5-methylcyclohexyl quinoline-2-carboxylate. Acta Cryst. E 2013, 70, o35-o36.

14. Jasinski, J.P.; Butcher, R.J.; Mayekar, A.N.; Yathirajan, H.S.; Narayana, B.; Sarojini, B.K. Synthesis, Crystal Structures and Theoretical Studies of Four Schiff Bases Derived from 4-Hydrazinyl-8-(trifluoromethyl) quinoline. J. Mol. Struct. 2010, 980, 172-181.

15. Allen, F.H.; Kennard, O.; Watson, D.G.; Brammer, L.; Orpen, A.G.; Taylor, R. Tables of Bond Lengths Determined by X-ray and Neutron Diffraction. Part I. Bond Lengths in Organic Compounds. J. Chem. Soc. Perkin Trans. 1987, 2, S1-S19.

16. Schmidt, J.R.; Polik, W.F. WebMO Pro Homepage, version 8.0.01e. Available online: http://www.webmo.net (accessed on 6 December 2014).

17. Frisch, M.J. Gaussian 03; Revision C01; Wallingford: New Haven, CT, USA, 2004.

18. Becke, A.D. Density-Functional Exchange-Energy Approximation with Correct Asymptotic-Behavior. Phys. Rev. A 1988, 38, 3098-3100.

19. Lee, C.; Yang, W.; Parr, R.G. Development of the Colle-Salvetti Correlation-Energy Formula into a Functional of the Electron Density. Phys. Rev. B Condens. Matter 1988, 37, 785-789. 
20. Hehre, W.J.; Random, L.; Schleyer, P.R.; Pople, J.A. Ab initio Molecular Orbital Theory; Wiley: New York, NY, USA, 1986.

21. Georgakopoulous, S.; Grondelle, R.V.; Zwan, G.V.D. Circular Dichroism of Carotenoides in Bacterial Light-harvesting Complexes: Experimental and Modeling. J. Biophys. 2005, 87, 3010-3022.

22. Guzin, A. Derivative Spectrophotometric Determination of Caffeine in Some Beverages. Turk J. Chem. 2002, 26, 295-302.

23. IGOR Pro (1988-2009), WaveMetrics. Available online: www.wavemetrics.com (accessed on 21 January 2015).

24. Oxford Diffraction. CrysAlis PRO and CrysAlis RED; Oxford Diffraction Ltd.: Abingdon, UK, 2010.

25. Dolomanov, O.V.; Bourhis, L.J.; Gildea, R.J.; Howard, J.A.K.; Puschmann, H. Smtbx. cif: A Comprehensive CIF Toolbox. J. Appl. Cryst. 2009, 42, 339-341.

26. Palatinus, L.; Chapuis, G. SUPERFLIP - A Computer Program for the Solution of Crystal Structures by Charge Flipping in Arbitrary Dimensions. J. Appl. Cryst. 2007, 40, 786-790.

27. Sheldrick, G.M. Crystal Structure Refinement with SHELXL. Acta Cryst. C 2015, 71, 3-8.

28. Spek, A.L. PLATON-A Multipurpose Crystallographic Tool; Ultrecht University: Ultrecht, The Netherlands, 2001.

(C) 2015 by the authors; licensee MDPI, Basel, Switzerland. This article is an open access article distributed under the terms and conditions of the Creative Commons Attribution license (http://creativecommons.org/licenses/by/4.0/). 